\title{
Retention as a function of natural language mediation and of time'
}

\author{
WILIAM RAY SMITH, University of Illinois, Urbana, Ill. \\ 61801
}

Subjects learned $20 \mathrm{CVC}$ pairs and reported the method used in learning (rote or natural language mediator, NLM). After 1, 3, or 9 days, recall was tested and method of learning was reported. Recall was virtually unchanged over 9 day's for those pairs for which the NLM reported at recall was the same as at acquisition. Retention was low for pairs learned by rote or with a NLM that was forgotten at recall, and decreased as the retention interval increased.

Although Reed (1918) long ago found that learning and retention are facilitated by natural language mediators (NLMs, i.e., any association $\mathrm{S}$ reports using in the learning of a pair of items), most experimental psychologists have ignored the possibility that such reports could be of value in predicting and explaining behavior. However, there has been a revival of interest in NLMs (e.g., Montague, Adams, \& Kiess, 1966; Adams \& McIntyre, 1967). These studies have shown that recall is high when the NLM is remembered at recall; when the NLM is forgotten, recall is even lower than that of rote items learned without an NLM. The purpose of the present study was to investigate the effects of NLMs on retention over extended periods of time.

\section{SUBJECTS}

Seventy-five University of Illinois female undergraduates were paid $\$ 2.50$ for their participation in the experiment. Twenty-five Ss were randomly assigned to each of the three retention groups.

\section{VERBAL MATERIALS}

Twenty items were selected from CVC pairs scaled for Associability (AS), or their probability of eliciting a NLM (Montague \& Kiess, 1968). Pairs were selected at random from those having moderate AS values (.383 to .583 on the AS scale for females; mean AS value of .500).

\section{PROCEDURE}

Cards with the verbal material typed on them were presented by means of an apparatus consisting of a vertical board with a slot for presenting the card to $S$ and a slot for $S$ to return the card to $\mathrm{E}$. Two Hunter interval timers activated a relay which produced a soft "click" signalling $E$ to present a card and a louder "click" signalling $S$ to return the card to $E$. A card was shown for $4.0 \mathrm{sec}$. Then $S$ was allowed $2.0 \mathrm{sec}$ to return the card to $\mathrm{E}$.

The correction procedure described by Battig (1965) was used to equate items for associative strength. In order to avoid having easy items learned early and then overlearned relative to difficult items, a trial in the correction procedure is defined as one correct recall of each item. Each trial began with one of three random orders of the list. In order to minimize overlearning of all the items, the acquisition session was terminated if there was perfect recall of all 20 items on their first presentation on a trial or after the third trial.

After either of the criteria for learning was reached, the stimulus CVC of each pair was presented individually, and S filled out a separate questionnaire for each pair, copying the stimulus trigram and writing the response CVC if she could. In order to assess the method of learning, space was provided for writing the NLM; if a NLM was not used, S indicated that the pair was learned by "rote." The self-paced recall test required from 3 to $5 \mathrm{~min}$.
After the retention interval, a self-paced recall test series like that at the end of the acquisition session was administered.

\section{RESULTS}

Two judges rated the change in NLMs over the retention interval so that recall could be related to change in or forgetting of NLMs. After discussing the criteria for inclusion in the various categories, the judges independently tabulated whether or not a NLM was used in acquisition and whether the response was recalled correctly. NLMs used in acquisition were compared with those used in recall and were assigned to one of the following learning categories: (1) Same or (2) Not-theSame if it was distinctly different from that reported at acquisition or if the NLM was forgotten at recall. The judges agreed on 935 of the pairs and negotiated a category on the remaining nine pairs.

Proportion correct at recall for each retention interval for each learning category as well as the frequencies on which the proportions are based are presented in Table 1. An overall analysis of variance showed that the proportion correctly recalled decreased as a function of length of retention interval $[F(2,51)=25.8, p<.001]$. Individual Scheffé comparisons revealed no significant difference in recall for the 1- and 3-day groups. However, significantly more forgetting occurred in the 9-day group than in either the 1 -day group $[F(2,153)=24.44$, $p<.001]$, or in the 3-day group $[F(2,153)=29.03$, $\mathrm{p}<.001]$

Inspection of Table 1 reveals that recall was highly related to category of learning. While correct recall was relatively low for items learned by Rote and Not-the-Same NLM, items with the Same NLM were correctly recalled at a high level. Recall of both Rote and Not-the-Same items was significantly lower than that of items with the Same NLM $[F(2,102)=231.33$, $p<.001]$. Length of retention interval and category of learning were found to interact significantly $[F(4,102)=5.12$, $\mathrm{p}<.005]$. Although for all three categories of learning retention decreased somewhat with increases in length of retention interval, the decrease was much sharper for items learned by Rote and for those with Not-the-Same NLM lusing Scheffé critical values, the difference between the 1-and 9-day intervals was not significant for the Same category,

Table 1

Proportion Correct Recall for Each Category of Learning for Each Retention Interval Group

\begin{tabular}{|c|c|c|c|c|}
\hline & $\begin{array}{l}\text { Same-Similar } \\
\text { NLM }\end{array}$ & $\begin{array}{l}\text { Category of } \\
\text { Not-the-Same } \\
\text { NLM }\end{array}$ & $\begin{array}{l}\text { Learning } \\
\text { Rote }\end{array}$ & $\begin{array}{l}\text { Group } \\
\text { Total }\end{array}$ \\
\hline One Day & $\begin{array}{l}301 / 308 \\
0.977\end{array}$ & $\begin{array}{l}16 / 23 \\
0.696\end{array}$ & $\begin{array}{l}99 / 137 \\
0.723\end{array}$ & $\begin{array}{l}416 / 468 \\
0.889\end{array}$ \\
\hline Three Days & $\begin{array}{l}262 / 269 \\
0.974\end{array}$ & $\begin{array}{l}29 / 47 \\
0.617\end{array}$ & $\begin{array}{l}119 / 158 \\
0.753\end{array}$ & $\begin{array}{l}410 / 474 \\
0.865\end{array}$ \\
\hline Nine Days & $\begin{array}{l}174 / 190 \\
0.916\end{array}$ & $\begin{array}{l}18 / 107 \\
0.168\end{array}$ & $\begin{array}{l}61 / 174 \\
0.351\end{array}$ & $\begin{array}{l}253 / 471 \\
0.537\end{array}$ \\
\hline $\begin{array}{l}\text { Category } \\
\text { Total for } \\
\text { All Groups }\end{array}$ & $\begin{array}{l}737 / 767 \\
0.961\end{array}$ & $\begin{array}{l}63 / 177 \\
0.356\end{array}$ & $\begin{array}{l}279 / 469 \\
0.595\end{array}$ & $\begin{array}{l}1079 / 1413 \\
0.764\end{array}$ \\
\hline
\end{tabular}

Note. The proportion is based on the ratio given which is the number of items correct over the number of items in the category for the retention group. 
$F(8,102)=6.75, p>.25$, but was significant for Rote, $\mathrm{F}(8,102)=33.52, \mathrm{p}<.001$, and for Not-the-Same NLM, $F(8,102)=39.48, p<.001]$. The difference between Rote and Not-the-Same NLM was negligible after 1 day, and, after 3 days and 9 days, retention for Not-the-Same tended to be lower though not significantly [Scheffé values of $F(8,102)=8.80, p>.25$ and $F(8,102)=10.88, p>.25$, respectively]. Not only did forgetting of items with Not-the-Same NLM increase with increasing retention interval, but also the frequency of Not-the-Same NLMs increased with longer retention intervals $(4.9 \%$ of all items for the 1-day group had Not-the-Same NLM, 9.9\% for the 3-day group, and $22.7 \%$ for the 9-day group).

\section{DISCUSSION}

The results of the present study supported previous investigations showing that the method a $S$ uses in learning paired associates is highly related to retention. In particular, the findings of Montague et al (1966) and Adams \& McIntyre (1967) were confirmed and extended. In the present study, the facilitative effect of NLMs was found to extend over a retention interval as long as 9 days. While the recall of pairs learned by rote or with an NLM that was forgotten at recall became increasingly poor with longer retention intervals, the pairs with the NLMs available at recall were correctly remembered over $90 \%$ of the time even after 9 days.

Natural language mediation may be thought of as an instance of transfer of training (Adams, 1967, pp. 86-88; Adams \& Montague, 1967). According to this view, the $S$ has a long history of using language, and when faced with the task of learning a pair of items he may try to integrate the pair with natural language habits already in his response repetoire. Thus, a high degree of associative strength is quickly achieved through its integration with existing language habits. Obviously, a S may not always have the ability or desire to integrate an item with his past language habits. In such cases rote learning is used. This is in no way incompatible with the view that learning can occur through the association of new items with old language habits.

The transfer of training hypothesis carried with it, implicitly, the explanation of reduced forgetting for mediated items. NLMs, representing the transfer of established habits to the new learning task, impart associative strength to the new material that decreases forgetting. Furthermore, mediated items are an NLM-item complex that has a relative uniqueness with respect to other language units and the chances of forgetting through interference theory of forgetting, but this seems reasonable because it is the most defensible theory of forgetting presently available (Adams, 1967).

\section{REFERENCES}

ADAMS, J. A. Human memory. New York: McGraw-Hill, 1967.

ADAMS, J. A., \& McINTYRE, J. S. Natural language mediation and all-or-none learning. Canadian Journal of Psychology, 1967, 21 , 436-449.

ADAMS, J. A., \& MONTAGUE, W. E. Retroactive inhibition and natural language mediation. Journal of Verbal Learning \& Verbal Behavior, $1967,6,528-535$.

BATTIG, W. F. Procedural problems in paired-associate learning research. Psychonomic Monograph Supplements, 1965, 1 (Whole No. 1).

MONTAGUE, W. E., ADAMS, J. A., \& KIESS, H. O. Forgetting and natural language mediation. Journal of Experimental Psychology, $1966,72,829-833$.

MONTAGUE, W. E., \& KIESS, H. O. The associability of CVC pairs. Journal of Experimental Psychology, 1968, 78, (Monograph Supplement, 2, Part 2).

REED, H. B. Associative aids: I. Their relation to learning, retention and other associations. Psychological Review, 1918, 25, 128-155.

\section{NOTE}

1. This report is based on a thesis submitted to the Graduate College of the University of Illinois in partial fulfillment of the requirement for the M.A. degree in psychology. The author wishes to thank Drs. Jack A. Adams and William E. Montague for their helpful advice and encouragement.

\section{(Continued from page 287)}

mediated concept learning over their performance in nonmediated concept learning $(t=0.684$, $d f=68)$. It may be concluded that highly intelligent $S s$ effectively used the information provided by the mediation condition, whereas Ss of lowest intelligence were not helped by the additional input.

Similar findings were in evidence for highest and lowest intelligence Ss when the performance measure was total errors. Significantly fewer errors in mediated concept learning were found for $S s$ of highest intelligence $(t=3.074$, $\mathrm{df}=78$, $p<.01)$, but not for Ss of lowest intelligence $(t=1.114$, $\mathrm{df}=68$ ). In contrast to the significant improvement in performance noted above for the trials measure, no significant reduction in errors was found during mediated concept learning for Ss of medium intelligence $(t=1.473, \mathrm{df}=80)$.

\section{DISCUSSION}

These findings indicate that $S$ s of high intelligence solve mediation problems by the use of symbolic processes which result in efficient information retrieval and problem solution. In contrast, Ss of lowest intelligence use the same processes for retrieving information in mediated concept learning that they employ in nonmediated learning. As a result, the Ss of lowest intelligence in the present experiment demonstrated no significant improvement in performance in mediated concept learning. The lesser effect found for the medium intelligence
Ss may have resulted from combining within this group scores of Ss who were similar to the highest intelligence group and others who were similar to the lowest intelligence group.

These data also provide information concerning the role of mediation in learning. A general mediation effect was found but further analysis indicated that this effect operated only for a subset of the Ss. The demonstration that mediation occurred for Ss of highest but not of lowest intelligence emphasizes the interaction of mediation conditions and individual differences. These findings suggest that mediation effects may not operate across all Ss as is often assumed.

\section{REFERENCES}

JACOBSON, L. I., DICKINSON, T. C., FLEISHMAN, J. M., \& HARAGUCHI, R. S. The relationship of intelligence and mediating processes to concept learning. Journal of Educational Psychology, in press, a.

JACOBSON, L. I., ELENEWSKI, J. J., LORDAHL, D. S., \& LIROFF, J. $H$. The role of creativity and intelligence in conceptualization. Journal of Personality \& Social Psychology, in press, $b$.

MEDNICK, S. A., \& FREEDMAN, J. L. Facilitation of concept formation through mediated generalization. Journal of Experimental Psychology, 1960, 60, 278-283.

\section{NOTE}

1. This research was supported by Research Grant MH14716-01 from the National Institute of Mental Health. We wish to express our thanks fo Neil Schneiderman for his assistance. 